\title{
Impact of Service Quality on the Satisfaction of Patients in Primary Health Care Centres in Erode District
}

\author{
C. Sengottuvel* \\ Assistant Professor, PG and Research Department of Commerce with CA, Salem Sowdeswari College, Salem, \\ Tamil Nadu, India; drcsengottuvel@gmail.com
}

\begin{abstract}
The present study aims to identify the service gap and relationship between the patients' expectation and perception in primary health care centres' service performance. Fourteen upgraded primary healthcare centres were selected through the simple random sampling technique and 300 sample respondents were used in the study. From the analysis, all the selected variables such as response, assurance, empathy, reliability and tangibility are highly influenced expectation and perception level of patients in utilizing health care centre. The analysis of the model, from the viewpoint of the expectation and perception among the patients, suggests that the variables such as response, assurance, empathy, reliability and tangibility showed significant impact on the expectation and perception of the patients. The study suggested that the periodical assessment is essential to prove the standard of quality of services. It helps to fulfil the expectation of patients in utilising PHC. At the earlier, the policy makers should set up the standard for primary health centre.
\end{abstract}

Keywords: Assurance, Empathy, Reliability and Tangibility, Service Quality

\section{Introduction}

Individuals remaining healthier and educated, plenty of and unbiased job availabilities, reliable and unobscured organisations, green practices, worthiness and safety to life are the prime symptoms of inclusive economic growth ${ }^{1}$. The association between health and growth always stand reciprocative, since health yields economic growth, and this again results in strong and healthy citizens. The health of a nation is perceived on the basis of longevity of life, child mortality rate, and general birth and death rates.

\section{Review of Literature}

Parasuraman et al. ${ }^{2}$ established ten key indicators of service quality namely reliability, responsiveness, competence, access, courtesy, communication, creditability, security, understanding and knowing the customer and tangibility to express SERVQUAL. Zethamal et al. ${ }^{3}$ exposed that the private sector hospitals were persistently providing unparalleled health services to achieve profitability and continuity. Anand et al. ${ }^{4}$ asserted that there was low satisfaction among patients attending government health facilities. Jayanthi Pandian et al. ${ }^{5}$ analysed the impact of the policies and newer practices leading to increased use of the PHCs for birthing care.

Though many studies were conducted on the aspect of measurement of service quality in various service industries, however, only a very few studies were found to be carried out in respect of the service quality of Primary Health Care Centres (PHCs) in Tamil Nadu. Hence, the present study focuses on the service quality of primary health care centres in Erode district of Tamil Nadu.

*Author for correspondence 


\section{Objective of the Study}

- To study the association between patients' expectations and perception of primary health care service performance.

\section{Methodology}

The study employed both primary and secondary data. The primary data were obtained by means of a well structured interview schedule. The schedule included the questions related to both personal factors comprising patients' income, nature of diseases and nature of treatment, patients' services, patients' problems etc., and the factors of service quality based on the SERVQUAL developed by Parasuraman et al. ${ }^{6}$ The interview schedule was designed for the patients in primary rural health care hospitals. The data were collected from both inside and outside patients. Data collected from primary and secondary sources were tabulated and treated with the appropriate statistical tools.

\subsection{Sample Design}

Basically Erode district was specified chosen for the intake of patients in primary health care centres. The data were collected from 300 respondents based on simple random sampling method representing 14 upgraded primary healthcare centres in Erode district. The data were presented in the form of tables which were systematically analyzed by using Chi-square test, Multiple Regression technique, and finally Structural Equation Modeling (SEM) was used to present the results with accuracy by using SPSS 17.0.

\subsection{Hypotheses of the Study}

There is a positive impact on expectation and perception of patients in utilizing primary health care centre.

\section{Validity of the Measurements}

\subsection{Hypothetical Model of the Association between Patients' Expectation and Perception}

Figure 1 depicts the developed hypothetical model yielding the proposed hypotheses.

\subsection{Testing of Model Fit}

\subsubsection{CMIN}

Table 1 shows the CMIN for the 'default model'. A significant Chi-square indicates satisfactory model fit.

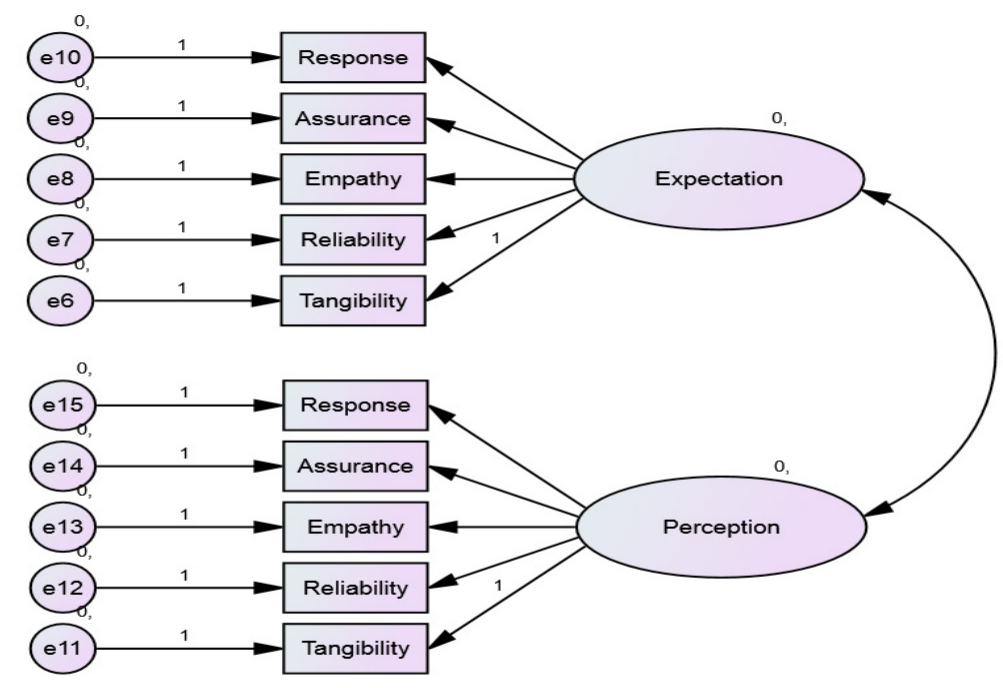

Figure 1. Hypotheses Supporting Research Model 
Table 1. CMIN

\begin{tabular}{llllll}
\hline Model & NPAR & CMIN & DF & P & CMIN/DF \\
\hline Default model & 31 & 159.124 & 34 & .000 & 4.680 \\
Saturated model & 65 & .000 & 0 & & \\
Independence model & 20 & 944.521 & 45 & .000 & 20.989 \\
\hline
\end{tabular}

Source: Computed from survey data

Table 2. Baseline Comparisons

\begin{tabular}{llllll}
\hline Model & $\begin{array}{l}\text { NFI } \\
\text { Delta1 }\end{array}$ & $\begin{array}{l}\text { RFI } \\
\text { rho1 }\end{array}$ & $\begin{array}{l}\text { IFI } \\
\text { Delta2 }\end{array}$ & $\begin{array}{l}\text { TLI } \\
\text { rho2 }\end{array}$ & CFI \\
\hline Default model & .832 & .777 & .863 & .816 & .861 \\
Saturated model & 1.000 & & 1.000 & & 1.000 \\
Independence model & .000 & .000 & .000 & .000 & .000 \\
\hline
\end{tabular}

Source: Computed from survey data

Table 3. RMSEA

\begin{tabular}{lcccc}
\hline Model & RMSEA & LO 90 & HI 90 & PCLOSE \\
\hline Default model & .011 & .094 & .129 & .000 \\
Independence model & .259 & .244 & .273 & .000 \\
\hline
\end{tabular}

Source: Computed from survey data

Table 1 shows the CMIN for the 'default model'. A significant Chi-square indicates satisfactory model fit. CMIN is Chi-square statistics comparing the default model and the independence model with the saturated model. The calculated value of Chi-square test is 159.124 on 34 degrees of freedom, which gives a p-value of 0.00 and this model is a good fit for the analysis. Further, the default model has been associated at 4.680 percent with saturated model and on the other hand, the independence model has been associated at 20.989 percent with saturated model.

\subsubsection{Baseline Comparisons}

The NFI (Normed Fit Index) also known as $\Delta_{1}$, is developed as the alternative to CFI (Comparative Fit Index), which is also known as the Bentler Comparative Fit Index ${ }^{7}$, compares the existing model fit with the null model which assumes that the latent variables correlate with the independent variables.

Table 2 highlights that the values of NFI is 0.832 , IFI is 0.777 and CFI is 0.861 , which confirm that the model is a good fit with the saturated and independent model.

\subsubsection{RMSEA}

Root Mean Square Error of Approximation (RMSEA) is the popular measure of fit, because it does not require comparison with the null model.

It could be noted from Table 3 that the RMSEA value is 0.011 which is lesser than 0.05 and hence the model has resulted as good fit.

\section{Resulted Hypotheses Model for the Association between Patients' Expectation and Perception}

The following path analysis as shown in Figure 2 is used to prove the selected hypotheses.

\subsection{Maximum Likelihood Estimates}

Table 4 shows the regression coefficient of the exogenous variables. It can be noted that the critical ratio of E1, E2, E3, E4, E5, P1, P2, P3, P4 and P5 are above the table value of 2.962 and it is significant at 1 percent level. From the analysis, it is concluded that all the selected variables such as response, assurance, empathy, reliability and tangibility have highly influenced expectation and perception level of patients in utilizing primary health care centre.

\subsection{Testing of Hypotheses}

Table 5 shows the proof of the hypotheses testing. 


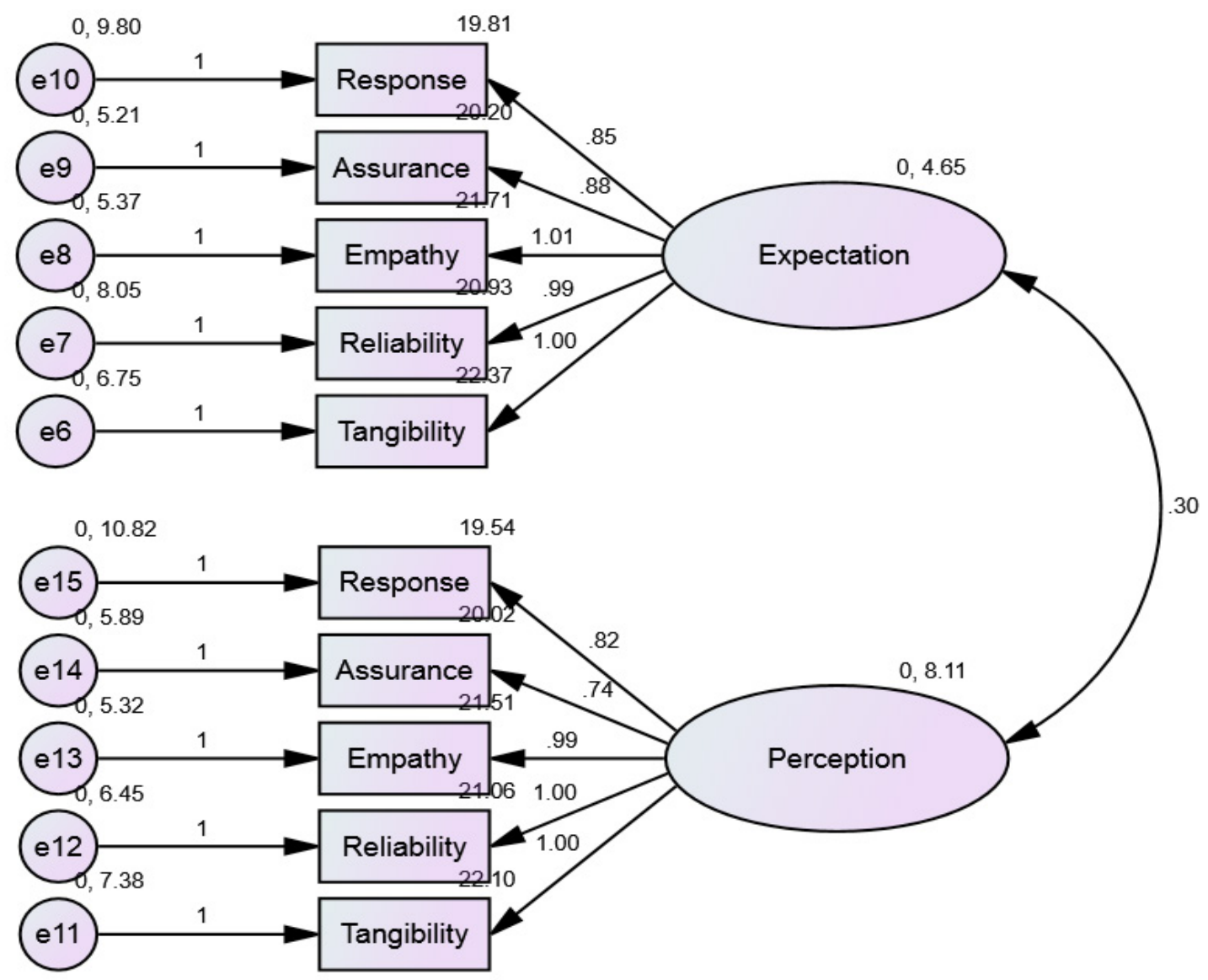

Figure 2. Resulted Hypotheses Model

Table 4. Regression Weights

\begin{tabular}{|c|c|c|c|c|c|c|c|}
\hline S. No. & Measured Variables & & $\begin{array}{l}\text { Latent } \\
\text { Variable }\end{array}$ & Estimate & S.E. & C.R. & $\mathbf{P}$ \\
\hline 1 & E1 & $<---$ & Expectation & 1.000 & & & \\
\hline 2 & E2 & $<---$ & Expectation & .994 & .127 & 7.836 & $* * *$ \\
\hline 3 & E3 & $<---$ & Expectation & 1.011 & .120 & 8.455 & $* * *$ \\
\hline 4 & $\mathrm{E} 4$ & $<---$ & Expectation & .878 & .108 & 8.135 & $* * *$ \\
\hline 5 & E5 & $<---$ & Expectation & .853 & .124 & 6.880 & $* * *$ \\
\hline 6 & $\mathrm{P} 1$ & $<---$ & Perception & 1.000 & & & \\
\hline 7 & $\mathrm{P} 2$ & $<---$ & Perception & .997 & .088 & 11.323 & $* * *$ \\
\hline 8 & P3 & $<---$ & Perception & .988 & .085 & 11.638 & $* * *$ \\
\hline 9 & P4 & $<---$ & Perception & .742 & .073 & 10.133 & $* * *$ \\
\hline 10 & P5 & $<---$ & Perception & .818 & .091 & 8.986 & $* * *$ \\
\hline
\end{tabular}

Source: Computed from survey data 
Table 5. Testing of Hypotheses

\begin{tabular}{|c|c|c|}
\hline Hypotheses & $\begin{array}{l}\text { Hypothetical } \\
\text { Relationship }\end{array}$ & Result \\
\hline $\begin{array}{l}\mathrm{H} 1: \text { There is a positive } \\
\text { impact of response } \\
\text { on expectation and } \\
\text { perception }\end{array}$ & Positive & Confirmed \\
\hline $\begin{array}{l}\mathrm{H} 2 \text { : There is a positive } \\
\text { impact of assurance } \\
\text { on expectation and } \\
\text { perception }\end{array}$ & Positive & Confirmed \\
\hline $\begin{array}{l}\mathrm{H} 3 \text { : There is a positive } \\
\text { impact of empathy } \\
\text { on expectation and } \\
\text { perception }\end{array}$ & Positive & Confirmed \\
\hline $\begin{array}{l}\mathrm{H} 4 \text { : There is a positive } \\
\text { impact of reliability } \\
\text { on expectation and } \\
\text { perception }\end{array}$ & Positive & Confirmed \\
\hline $\begin{array}{l}\text { H5 : There is a positive } \\
\text { impact of tangibility } \\
\text { on expectation and } \\
\text { perception }\end{array}$ & Positive & Confirmed \\
\hline
\end{tabular}

\section{Key Finding}

From the path diagram, the measured variables with latent variable of expectation and perception are having positive relationship and also significant at 1 percent level. The analysis of the model, from the viewpoint of the expectation and perception among the patients, suggests that the variables such as response, assurance, empathy, reliability and tangibility are showing significant impact on the expectation and perception of the patients. Structural equation modeling analysis shows that the measured variables with latent variable of expectation and perception are having positive relationship and also significant at 1 percent level.

\section{Suggestion}

The study found that the variables such as response, assurance, empathy, reliability and tangibility are showing significant impact on the expectation and perception of the patients. So, it is suggested that the periodical assessment is essential to prove the standard of quality of services. It helps to fulfil the expectation of patients in utilising PHCs. At the earlier, the policy makers should set up the standard for primary health care centres.

\section{Conclusion}

The study has exposed that the service quality variables namely, response, assurance, empathy, reliability and tangibility are significantly impacting the expectation and perception of the patients relying on PHCs in Erode district of Tamil Nadu. Hence, to assure dispensing sufficient health care facilities inclusive of the services of the medical and paramedical professionals in PHCs, continuous observing, regulating and controlling of the functions of PHCs is very much essential. Also providing primary sanitation in both rural and urban localities must be made mandatory. Besides, the government should intensively disseminate health education to the mass in villages. On the whole, nurturing better health of the citizens, especially the rural residents, is the utmost obligation of the dutybound government.

\section{References}

1. Zamil AM, Areiqat AY, Tailakh W. The impact of health service quality on patients' satisfaction over private and public hospitals in Jordan: A comparative study. International Journal of Marketing Studies. 2012 Feb; 4(1):123-37.

2. Parasuraman A, Zethamal VA, Berry LL. A conceptual model of service quality and its implications for future research. Journal of Marketing. 1985; 49:41-50. Crossref

3. Zeithamal VA, Berry LL, Parasuraman A. The behavioral consequence of service quality. Journal of Marketing.1996; 60:31-52. Crossref

4. Anand D, Kaushal S, Gupta SC. A study on status of client satisfaction in patients attending government health facilities in Agra District. Indian Journal of Community Health. 2012 Jul; 24(3):209-14.

5. Pandian J, Suresh S, Desikachari BR, Padmanaban P. Increased utilization of primary health care centers for birthing care in Tamil Nadu, India: A visible impact of policies, initiatives and innovations. Journal of Family Medicine and Primary Care. 2013 Oct-Dec; 2(4):32933. Crossref PMid: 26664836 PMCid:PMC4649873

6. Parasuraman A, Zethamal VA, Berry LL. op.cit.

7. Hu LT, Bentler PM. Cut off criteria for fit indexes in covariance structural analysis: Conventional criteria versus new alternatives. Structural Equation Model. $6: 1-55$ 